\title{
The Effects of Lightning Strikes and High Current on Aerospace Materials
}

\author{
Luther. M. Gammon, Natalya Baxter, Anthony Falcone, Christopher A Meyer, \\ Henry Oberson, Evan R Stark \\ The Boeing Company P.O. Box 3707 MC 19-HP, Seattle, Washington 98124
}

This paper covers microscopic analysis of the lightning strike effect and high current on a wide range of aerospace materials. It also covers the macro- and micro-evaluation techniques used in the laboratory.

On any material where an electrical arc has traversed, the arc will have damaged or altered the material. This damaged region can undergo a heat-induced phase transformation or other effects. In some cases, material is vaporized or oxidized. The vaporized material is easy to qualify. A more difficult task is to qualify and quantify material that has undergone EME-induced damage in metals. A phase transformation may results in a loss of mechanical properties.

During a Seattle thunderstorm on the evening of July $16^{\text {th }} 1999$, on a final approach for landing a 737-800 sustained a major lightening strike. Based on the pattern of physical damage, the lightening bolt appeared to enter the aircraft through the open nose landing gear wheel well. It passed internally through the full length of the fuselage and exited the aircraft though the antenna mounted at the aft, top edge of the vertical fin. Damage to the Alclad 2024-T3 fuselage structure was primarily in the form of melting. It partially melted widely separated rivets and adjacent fuselage skin. The damage was contained within a $24 \mathrm{~mm}$ cutout.

The damage observed by the unaided eye is always accompanied with microstructural damage within the affected area. A phase transformation can be documented in some materials by NDI tools like conductivity (in the case of aluminum 2024). However because the phase transformation is localized in the few grain boundaries it would be difficult to qualify the affected zone using conductivity. The material-graph cross-section is an excellent way to quantify and qualify the extent of the damage. For 2000 and 7000 aluminum alloys 10-10 etchant will etch the polished cross-section. The key is to etch the sample just enough to differentiate the unaffected grain bounders from tri-axial eutectic melting. (Figure 1) If etched with the full strength Keller's etchant can etch out the grain boundaries and it would not be possible to observe the difference in the microstructure.

In composites, internal arcing damage can be detected by radiographic, electronic thermograph, ultrasonic, pulse-echo and tap test techniques. Light optical microscopy of laboratory electromagnetic effects tests show the extent of a ply dis-bond, inter-ply arcing and micro-cracking. (Figure 2) Epi-florescent microscopy is a preferred way to examine the defects and subtle features.

(Figure 3) 


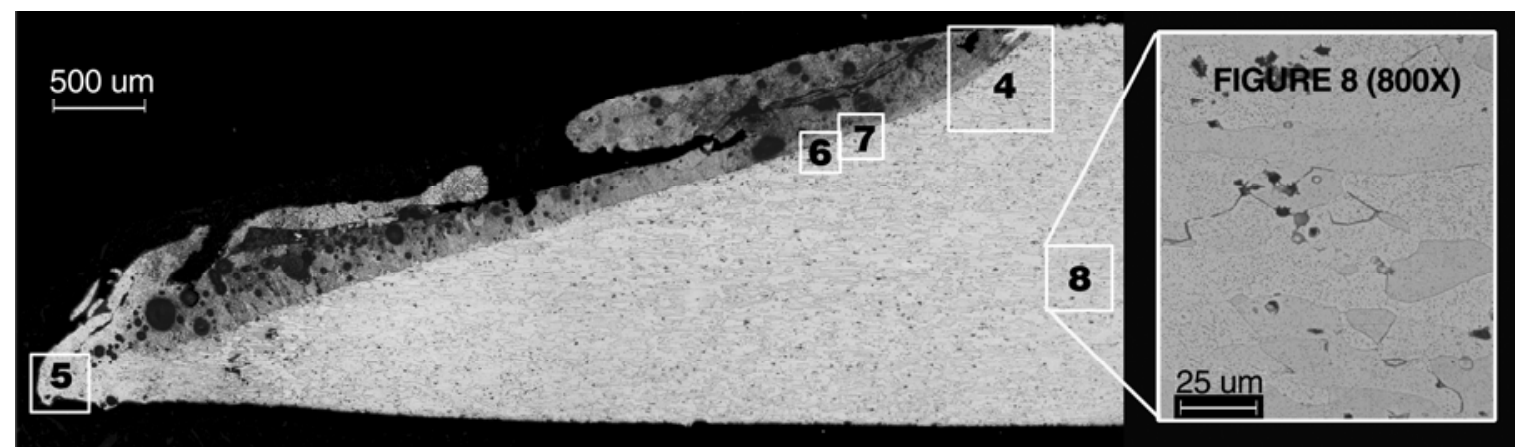

Figure 1 A cross-section of aluminum 2024 T3 damage zone. Note the sample is etched just enough to differentiate rosettes, and the unaffected grain boundaries from try-axial eutectic melting. 10-10 Enchant: step 1(10sec. $0.5 \mathrm{ml}$. HF, $15.5 \mathrm{ml}$. $+\mathrm{HNO}_{3}, 3.5 \mathrm{gm}$. $\left.\mathrm{CrO}_{3 .+} 9 \mathrm{ml} . \mathrm{H}_{2} 0\right)$ Step 2 (10 sec. $25 \%$ Keller's)

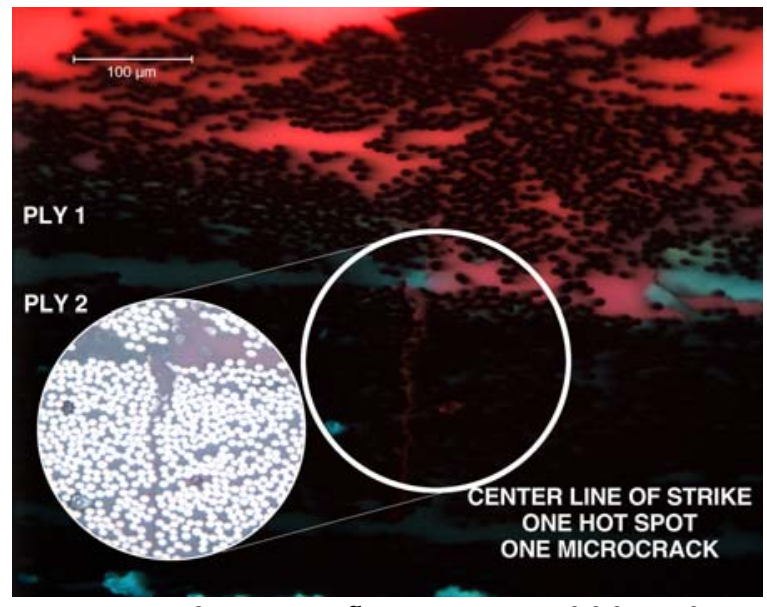

Figure 2 Epi-florescent 390-440 excitation. Carbon fiber lightning strike cross-section from the damage zone impregnated with fluorescing epoxy.

- Mount the cross-section in the fluorescing epoxy containing 7\% methanol hydrated Rhodamine

- Apply a florescent penetrate like Mangaflux ZYGLO ZL-H, or ZL67 to the polished face.

- Examine with Epi-florescent light (390-440 excitation)

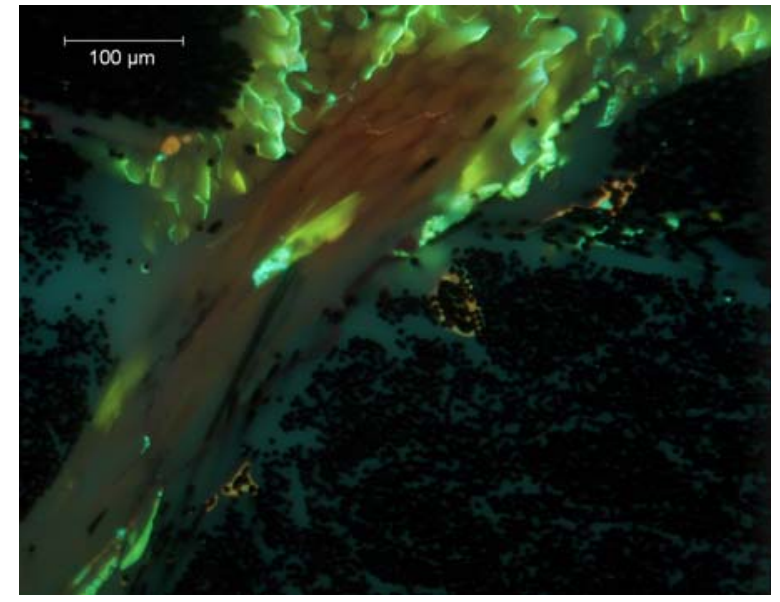

Figure 3 Epi-florescent 390-440 excitation. Kevlar stitch in carbon fiber composite lightning strike cross- section. This sample had a florescent penetrant ZYGLO-H applied to the polished surface and back polished.

There are a large number of different types of structural airspace materials in use today. All materials have special challenges for research and diagnostic of their electro-magnetic effects. 